\title{
Molecular Docking based Analysis to Elucidate DNA- 1, 2- Phenylenediamine Schiff's Base Derivative Interactions Promotes Chemotherapeutic Intervention
}

\author{
Inass A Sadawe ${ }^{1}$, Abdulathim A A Alshoushan ${ }^{2}$, Nisreen H Meiqal ${ }^{1}$, Salah M Bensaber ${ }^{1}$, Anton \\ Hermann $^{3}$, Abdul M Gbaj ${ }^{*}$ \\ ${ }^{1}$ Department of Medicinal Chemistry, Faculty of Pharmacy, University of Tripoli, Libya \\ ${ }^{2}$ Food and Drug Control Centre (LFDA), Tripoli, Libya \\ ${ }^{3}$ Department of Biosciences, University of Salzburg, Salzburg, Austria
}

\author{
*Corresponding Author: Abdul M Gbaj, Department of Biosciences, University of Salzburg, Salzburg, \\ Austria
}

\begin{abstract}
DNA constitutes a powerful target for chemotherapeutic intervention in human cancers, particularly for those where high proliferation rates of tumor cell types have resulted in sensitivity to drugs, which block replication and transcription of their DNA. Molecular detection of particular DNA sites by small molecules is an essential dilemma in drug design. Polycyclic heterocycles having a planar structure can be efficient pharmacophore moieties for DNA-interactive drugs because they can insert between the stacked base paired oligonucleotides or interact with grooves. Despite DNA being a significant target for numerous drugs, most of the docking programs are validated only for proteins and their ligands. In this paper, AutoDock 4.0 was used to perform self-dockings and cross dockings between seven DNA targets and five ligands belonging to 1,2-Phenylenediamine Schiff's base derivatives. AutoDock is able to correctly recognize main DNA binding modes. The obtained docking results are in absolute agreement with experimental data from the literature. In conclusion, our data that computational approaches on synthesized proposed ligands will contribute to select the most promising candidates as DNA-interactive drugs that have antitumor activity.
\end{abstract}

Keywords: DNA-interactive agents, binding energy, molecular docking, chemotherapeutic intervention

\section{INTRODUCTION}

DNA represents a major target for chemotherapeutic strategy in human cancers, particularly for those where elevated proliferation rates of some tumor cell types have resulted in sensitivity to drugs, which obstruct transcription and replication of their DNA [1]. Molecular identification of DNA by small molecules is anessentialdilemma in drug design. Many polycyclic heterocycles having a planar structure could be efficient pharmacophore moieties for DNA-interactive drugs since they are capable to insert themselves between the stacked base paired oligonucleotides. Furthermore, if they have appropriate side chains, additional interactions of these ligands with other important architectural characteristic of DNA can be predicted [2;3]. We have recently reported on using microwave assisted synthesis and antimicrobial evaluation of symmetrical 1,2-Phenylenediamine Schiff's base derivatives finding that some of the synthesized compounds showed antibacterial and antifungal activity [4]. Now we intended to explore how different structural features of 1,2-Phenylenediamine Schiff's base derivatives can affect the DNA binding capability. Here we present molecular modeling studies of 1,2-Phenylenediamine Schiff's base derivatives using seven DNA targets. We hypothesized that this interaction can help to recognize the molecular mechanism of 1,2-Phenylenediamine Schiff's base derivatives action and may serve as a basis for understanding the molecular mechanism of action of the 1,2-Phenylenediamine Schiff's base derivatives and can help to design of new chemotherapeutic molecules.

\section{Materials AND Methods}

\subsection{Molecular Docking Study}

MGL (Molecular Graphics Laboratory) tools 1.5.4 with AutoDock4 and AutoGrid 4.0 were used to set up and exert blind docking calculations between various 1,2-Phenylenediamine Schiff's base derivatives and DNA sequences. DNA sequences: 
Molecular Docking based Analysis to Elucidate DNA- 1, 2-Phenylenediamine Schiff's Base Derivative Interactions Promotes Chemotherapeutic Intervention

DNA $\left(5 '-\mathrm{D}\left({ }^{*} \mathrm{CP} * \mathrm{GP} * \mathrm{CP} * \mathrm{GP} * \mathrm{AP} * \mathrm{AP} * \mathrm{TP} * \mathrm{TP} * \mathrm{CP} * \mathrm{GP} * \mathrm{CP} * \mathrm{G}\right)-3\right.$ ') (PDB ID: 1bna),

DNA $\left(5 '-\mathrm{D}\left({ }^{*} \mathrm{CP} * \mathrm{GP} * \mathrm{CP} * \mathrm{AP} * \mathrm{AP} * \mathrm{AP} * \mathrm{TP} * \mathrm{TP} * \mathrm{TP} * \mathrm{GP} * \mathrm{CP} * \mathrm{G}\right)-3\right.$ ') (PDB ID: 102d),

DNA $\left(5^{\prime}-\mathrm{D}\left({ }^{*} \mathrm{CP} * \mathrm{GP} * \mathrm{TP} * \mathrm{AP} * \mathrm{CP} * \mathrm{G}\right)-3\right.$ ') (PDB ID: 1k2j),

DNA $\left(5 '-\mathrm{D}\left({ }^{*} \mathrm{CP} * \mathrm{GP} * \mathrm{CP} * \mathrm{GP} * \mathrm{AP} * \mathrm{TP} * \mathrm{AP} * \mathrm{TP} * \mathrm{CP} * \mathrm{GP} * \mathrm{CP} * \mathrm{G}\right)-3\right.$ ') (PDB ID: 1dne),

DNA $\left(5 '-\mathrm{D}\left({ }^{*} \mathrm{CP} * \mathrm{GP} * \mathrm{CP} * \mathrm{AP} * \mathrm{GP} * \mathrm{AP} * \mathrm{AP} * \mathrm{TP} * \mathrm{TP} * \mathrm{CP} * \mathrm{GP} * \mathrm{CP} * \mathrm{G}\right)-3\right.$ ') (PDB ID: 1d31),

DNA (5'-D $\left({ }^{*} \mathrm{CP} * \mathrm{GP} * \mathrm{CP} * \mathrm{GP} * \mathrm{AP} * \mathrm{AP} * \mathrm{TP} * \mathrm{TP} * \mathrm{CP} * \mathrm{GP} * \mathrm{CP} * \mathrm{G}\right)-3$ ') (PDB ID: 2gvr), and

DNA $\left(5 '-\mathrm{D}\left({ }^{*} \mathrm{CP} * \mathrm{GP} * \mathrm{TP} * \mathrm{AP} * \mathrm{CP} * \mathrm{G}\right)-3\right.$ ') (PDB ID: 2des) were obtained from the Protein Data Bank and were used for the docking studies. 1,2-Phenylenediamine Schiff's base derivatives structures were drawn and optimized using ChemDraw Ultra (version 8.0, Cambridgesoft Com., USA). Chem3D Ultra was used to convert 2D into 3D structures and the energy was minimized using the semiempirical AM1 method which is based on the Neglect of Differential Diatomic Overlap (NDDO) integral approximation. The molecular dockings of SW (1,2-Phenylenediamine Schiff's Base derivatives) compounds with B-DNAs (B: right-handed double helix DNA) were accomplished by Auto Dock 4.2 software from the Scripps Research Institute (TSRI) (http://autodock.scripps.edu/). Firstly, the polar hydrogen atoms were added into B-DNA molecules. Then, the partial atomic charges of the B-DNA and SW molecules were calculated using Kollman methods [5]. In the process of molecular docking, the grid maps of dimensions $(62 \AA$ X $62 \AA$ X $62 \AA)$ with a grid-point spacing of $0.376 \AA$ and the grid boxes centered. The number of genetic algorithm runs and the number of evaluations was set to 100 . All other parameters were default settings. Cluster analysis was performed on docking results by using a root mean square (RMS) tolerance of $2.0 \AA$, dependent on the binding free energy. Lastly, the dominating configuration of the binding complex of SW compounds and BDNA fragments with minimum binding energy can be determined. Taxol was used as a reference as it is a successful drug that is used for the treatment of various cancers and it binds to DNA grooves throughout the eight-membered taxane core ring, with the three phenyl rings pointing away from the core eight-membered ring. In addition, taxol has been reported to interact with tubulin leading to tumour cell death [6;7].

\subsection{Binding Energy}

To molecular docking simulation method is primarily validated on basis of the obtained binding energy. The predefined range of binding energy is supposed to be in the range between -5 to -15 $\mathrm{Kcal} / \mathrm{mol}$ to productively validate the molecular docking process.

\subsection{General Procedure for Synthesis of Schiff's Bases (Sw1-Sw7)[4]}

The Schiff's base was prepared as described before by our group by reaction of one mole of phenylenediamine and two moles of substituted aromatic aldehydes (Table 1) [4]. All reactants were mixed together and a minimum amount of ethanol was added $(2-3 \mathrm{ml})$. This mixture was subjected to microwave irradiation at 350 watt for 2-3 minutes at $60{ }^{\circ} \mathrm{C}$. The development of the reaction was watched on thin layer chromatography. The mixture was left for cooling and the solid product (crude) was gathered by filtration and washed four times with ethanol and vacuum dried. The gained product was re-dissolved in ethanol for recrystallization and dried to give a pure product (Scheme 1). The crystalline products obtained were characterized as published previously by FTIR, 1H NMR [4].

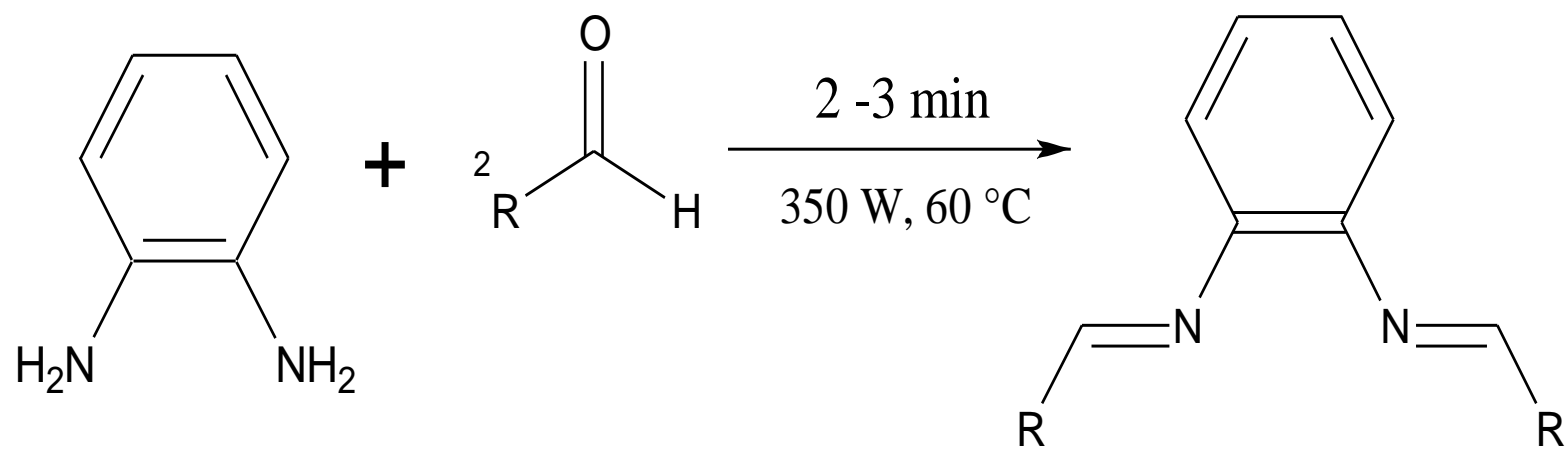

Scheme1. General scheme for the synthesis of Schiff's base compounds $\mathbf{S w 1 - S w 7 . ~}$ 
Molecular Docking based Analysis to Elucidate DNA- 1, 2-Phenylenediamine Schiff's Base Derivative Interactions Promotes Chemotherapeutic Intervention

Table1. Chemical structures of aromatic aldehydes used for chemical synthesis [4].

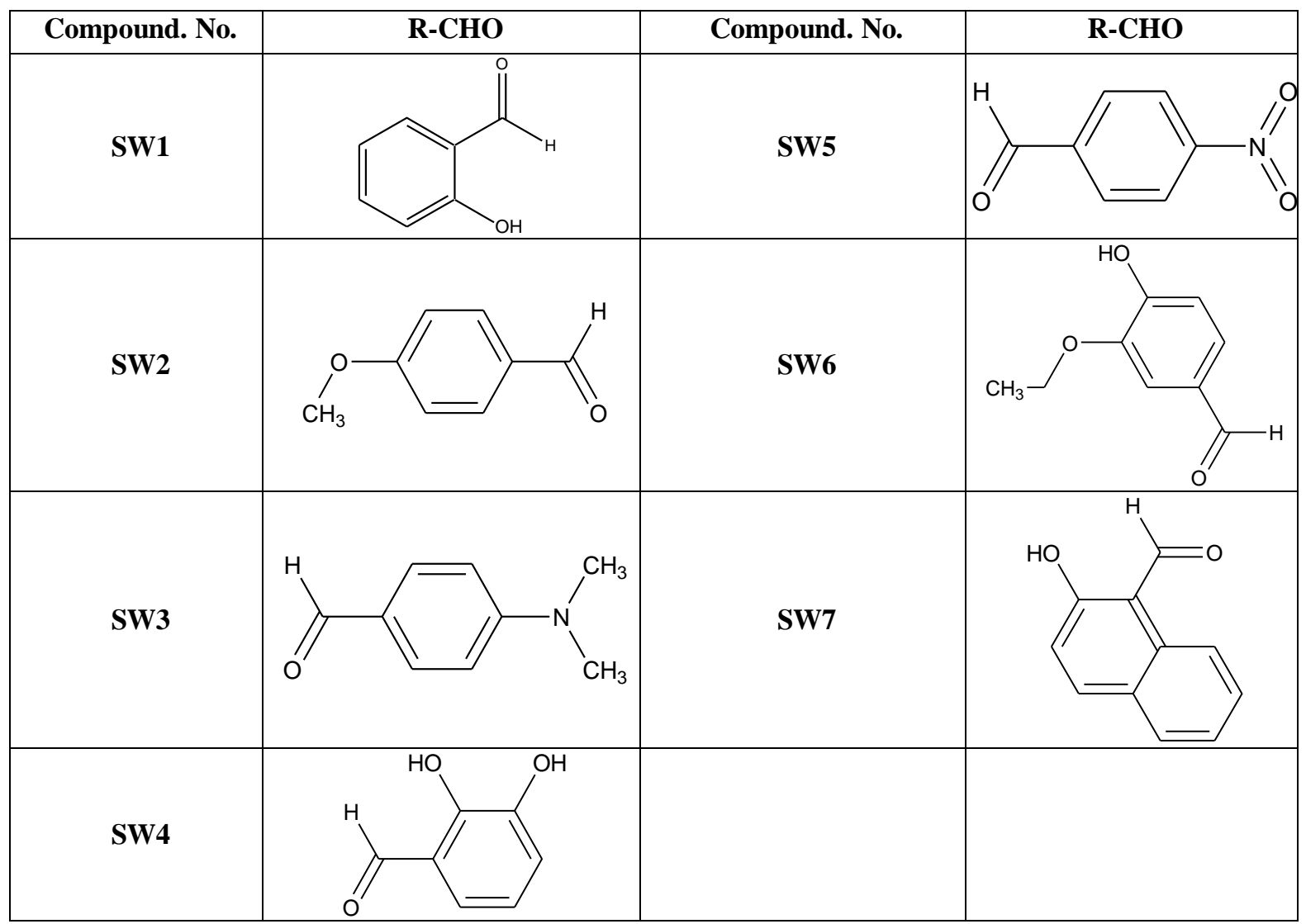

\section{RESULTS AND DISCUSSION}

\subsection{Molecular Docking Analysis}

Table 2 shows the binding energies of SW compounds and DNAs fragments obtained by the molecular docking strategy. In this study, molecular dockings of the SW compounds with seven BDNA fragments were performed using Auto Dock 4.2 to investigate the binding mode of SW compounds with B-DNA and to obtain information about interaction forces between SW compounds and DNA. SW compounds and DNA were kept as flexible molecules and were docked into seven forms of rigid B-DNA fragments to obtain the preferential binding site to SW compounds on BDNAs. The molecular docking results are shown in Table 2. The modeling studies showed that there are van der Waals, hydrogen bonding and electrostatic interactions between SW compounds and DNAs. The contribution of van der Waals and hydrogen bonding interaction is much greater than that of the electrostatic interaction because the sum of van der Waals energy, hydrogen bonding energy and desolvation free energy is larger than the electrostatic energy, which is consistent with the literature [8;9].

Some of the binding energies obtained by performing molecular docking simulation of the SW compounds with the seven DNA fragments did not lie in the predefined range of -5 to $-15 \mathrm{kcal} / \mathrm{mol}$ (Table 2). The obtained binding energy results demonstrate that the affinity of SW compounds for their "preferred"' sites is modulated by the local DNA sequence. In some cases this effect is relatively small, while in others cases, as in SW5, SW6 and SW7 the effect is dramatic. Since these sequence effects lie outside the principal binding sites for these ligands, they may reflect changes in the local DNA structure and/or dynamics. This is similar to those seen in protein-DNA interactions [10;11].

Table2. Various energies in the binding process of SW compounds with DNAs obtained from molecular docking. The unit of all energies $(\Delta G)$ is $\mathrm{kcal} / \mathrm{mol}$.

\begin{tabular}{|c|c|c|c|c|c|c|c|}
\hline $\begin{array}{l}\mathrm{c} \\
\mathrm{p}\end{array}$ & $\begin{array}{c}\text { 1bna } \\
\text { DNA }\left(5^{\prime}-\right. \\
\mathrm{D}\left(* \mathrm{CP} * \mathrm{GP}^{*} \mathrm{C}\right. \\
\mathrm{P}^{*} \mathrm{GP} * \mathrm{AP} * \mathrm{AP}\end{array}$ & $\begin{array}{c}\text { 102d } \\
\mathrm{DNA}\left(5^{\prime}-\right. \\
\mathrm{D}(* \mathrm{CP} * \mathrm{GP} \\
* \mathrm{CP}^{*} \mathrm{AP} * \mathrm{~A}\end{array}$ & $\begin{array}{c}1 \mathrm{k} 2 \mathbf{j} \\
\mathrm{DNA}(5 \\
'- \\
\mathrm{D}\left({ }^{*} \mathrm{CP}\right.\end{array}$ & $\begin{array}{c}\text { 1dne } \\
\text { DNA }\left(5^{\prime}-\right. \\
\mathrm{D}\left(* \mathrm{CP} * \mathrm{GP}^{*} \mathrm{C}\right. \\
\mathrm{P} * \mathrm{GP} * \mathrm{AP} * \mathrm{TP}\end{array}$ & $\begin{array}{c}1 \mathrm{~d} 31 \\
\mathrm{DNA}\left(5^{\prime}-\right. \\
\mathrm{D}\left(* \mathrm{CP}^{*} \mathrm{GP}^{*} \mathrm{CP}\right. \\
* \mathrm{AP}^{*} \mathrm{GP} * \mathrm{AP}^{*}\end{array}$ & $\begin{array}{c}\text { 2gvr } \\
\text { DNA }\left(5^{\prime}-\right. \\
\mathrm{D}\left({ }^{*} \mathrm{CP} * \mathrm{GP} * \mathrm{C}\right. \\
\mathrm{P}^{*} \mathrm{GP}^{*} \mathrm{AP} * \mathrm{AP}\end{array}$ & $\begin{array}{c}2 \text { des } \\
\text { DNA } \\
\left(5^{\prime}-\right. \\
\mathrm{D}\left({ }^{*} \mathrm{CP}\right.\end{array}$ \\
\hline
\end{tabular}


Molecular Docking based Analysis to Elucidate DNA- 1, 2-Phenylenediamine Schiff's Base Derivative Interactions Promotes Chemotherapeutic Intervention

\begin{tabular}{|c|c|c|c|c|c|c|c|}
\hline & $\begin{array}{l}{ }^{* \mathrm{TP}} * \mathrm{TP} * \mathrm{CP} * \\
\left.\mathrm{GP} * \mathrm{CP} * \mathrm{G})-3^{\prime}\right)\end{array}$ & $\begin{array}{l}* A P * T P * \\
\text { TP*TP*GP } \\
* \text { (CP*G)-3') }\end{array}$ & $\begin{array}{c}{ }^{*} \mathrm{GP} * \mathrm{~T} \\
\mathrm{P}^{*} \mathrm{AP} \\
\mathrm{CP} * \mathrm{G})- \\
\left.3^{\prime}\right)\end{array}$ & $\begin{array}{l}* \mathrm{AP}^{*} \mathrm{TP} * \mathrm{CP} * \\
\left.\mathrm{GP} * \mathrm{CP} * \mathrm{G})-3^{\prime}\right)\end{array}$ & $\begin{array}{l}\mathrm{AP} * \mathrm{TP} * \mathrm{TP} * \mathrm{CP} \\
\left.\left.*^{*} \mathrm{CP}^{*} \mathrm{CP} * \mathrm{G}\right)-3^{\prime}\right)\end{array}$ & $\begin{array}{l}{ }^{* \mathrm{TP}} * \mathrm{TP} * \mathrm{CP} * \\
\left.\mathrm{GP} *\left(\mathrm{P}^{*} \mathrm{G}\right)-3^{\prime}\right)\end{array}$ & $\begin{array}{c}{ }^{*} \mathrm{GP}^{*} \mathrm{~T} \\
\mathrm{P}^{*} \mathrm{AP} \\
\left.\mathrm{CP}^{*} \mathrm{G}\right) \\
\left.-3^{\prime}\right)\end{array}$ \\
\hline $\begin{array}{l}\mathrm{S} \\
\mathrm{W} \\
1\end{array}$ & -7.58 & -7.18 & -4.77 & -5.95 & -5.01 & -4.5 & -7.4 \\
\hline $\begin{array}{l}\mathrm{S} \\
\mathrm{W} \\
2\end{array}$ & -7.45 & $\begin{array}{l}-7.07 \\
\end{array}$ & -7.13 & -5.09 & -6.73 & -7.53 & -6.94 \\
\hline $\begin{array}{l}\mathrm{S} \\
\mathrm{W} \\
3 \\
\end{array}$ & -5.78 & -5.1 & -5.52 & -6.3 & -4.66 & -4.81 & -7.6 \\
\hline $\begin{array}{l}\mathrm{S} \\
\mathrm{W} \\
4\end{array}$ & -5.59 & -5.12 & -5.56 & -5.05 & -5.13 & -4.61 & -7.46 \\
\hline $\begin{array}{l}\text { S } \\
\mathrm{W} \\
5\end{array}$ & -4.85 & -4.07 & -7.2 & -3.43 & -5.95 & -3.21 & -7.15 \\
\hline $\begin{array}{l}S \\
W \\
6\end{array}$ & -6.13 & $\begin{array}{l}-4.89 \\
\end{array}$ & -5.14 & -5.24 & -4.29 & -4.57 & -7.21 \\
\hline $\begin{array}{l}\text { S } \\
\mathrm{W} \\
7\end{array}$ & -7.13 & -6.41 & -4.76 & -5.23 & -6.38 & -5.28 & -9.2 \\
\hline $\begin{array}{l}\mathrm{T} \\
\mathrm{a} \\
\mathrm{x} \\
\mathrm{o} \\
1\end{array}$ & -1.16 & -3.24 & +1.26 & $\begin{array}{l}-0.69 \\
\end{array}$ & -2.4 & -2.78 & -1.58 \\
\hline
\end{tabular}

Molecular docking is used for virtual screening of SW compounds employing binding affinity and the best orientation possible with respect to the target DNA. To illustrate the DNA-SW compounds interactions an example from the series was chosen (SW7 compound). The SW7- DNA interactions are shown in Figure 1. SW7 compound showed a good binding energy $(-5.23 \mathrm{kcal} / \mathrm{mol}$,) when compared to standard taxol $(-0.69 \mathrm{kcal} / \mathrm{mol})$ as mentioned in Table 2 . The chemical structure of the SW7 with atom numbering is shown in Figure 1A. The double helical structure of 1dne (Figure 1B), for example, is due largely to the hydrogen bonding between the base pairs, which link one complementary strand to the other. Figure 1B shows four hydrogen bonds between SW7 and 1dne fragment in the minor groove. The four hydrogen bonds were AP5:N6 (of 1dne, as H-bond donor) and O20 (of SW7, as H-bond acceptor); AP5:N6 (of 1dne, as H-bond donor) and O35 (of SW7, as H-bond acceptor); H9 (of SW7, as H-bond donor) and TP20:O4 (of 1dne, as H-bond acceptor); H24 (of SW7, as H-bond donor) and GP4:O6 (of 1dne, as H-bond acceptor).

All SW compounds studied in this paper were bound to the minorgroove of the seven DNA fragments. This binding often has cytotoxic activity because they interfere with the binding of proteins necessary for DNA replication and transcription. In the literature compounds that bind to the minor groove of DNA have proven to be very useful as antitumor agents because they selectively kill rapidly-dividing cells [12-14]. This has encouraged efforts to design molecules that bind at designated sites in the minor groove. It is thought that groove binders with increased selectivity will produce a greater biological response for a given dose (and consequently have fewer toxic and side effects) than non-selective groove binders [12-14]. Molecules that target particular DNA sites also have the prospective to be used for the selective suppression of transcription from fastidious gene sequences [15]. The complexes of SW compounds and DNA fragments could be stabilized by hydrogen bonding upon minor groove binding. This assumption is confirmed by the literature studies as it has been reported that the synthetic polycarboxamides consisting of N-methyl-3-hydroxypyrrole $(\mathrm{Hp}), \mathrm{N}-$ methylimidazole (Im), N-methylpyrrole (Py), and beta-alanine (beta) showed strong and sequencespecific interaction with the DNA minor groove when they form hairpin structures with side-by-side antiparallel motifs [16;17]. In the synthetic polycarboxamides report the researchers found new 
conjugates containing two ligands linked to the same terminal phosphate of the DNA strand. The polycarboxamides are inserted into the minor groove of a duplex in a parallel or antiparallel orientation. The obtained stabilization of DNA duplexes by two attached minor groove ligands was confirmed by thermal denaturation studies [16;17].
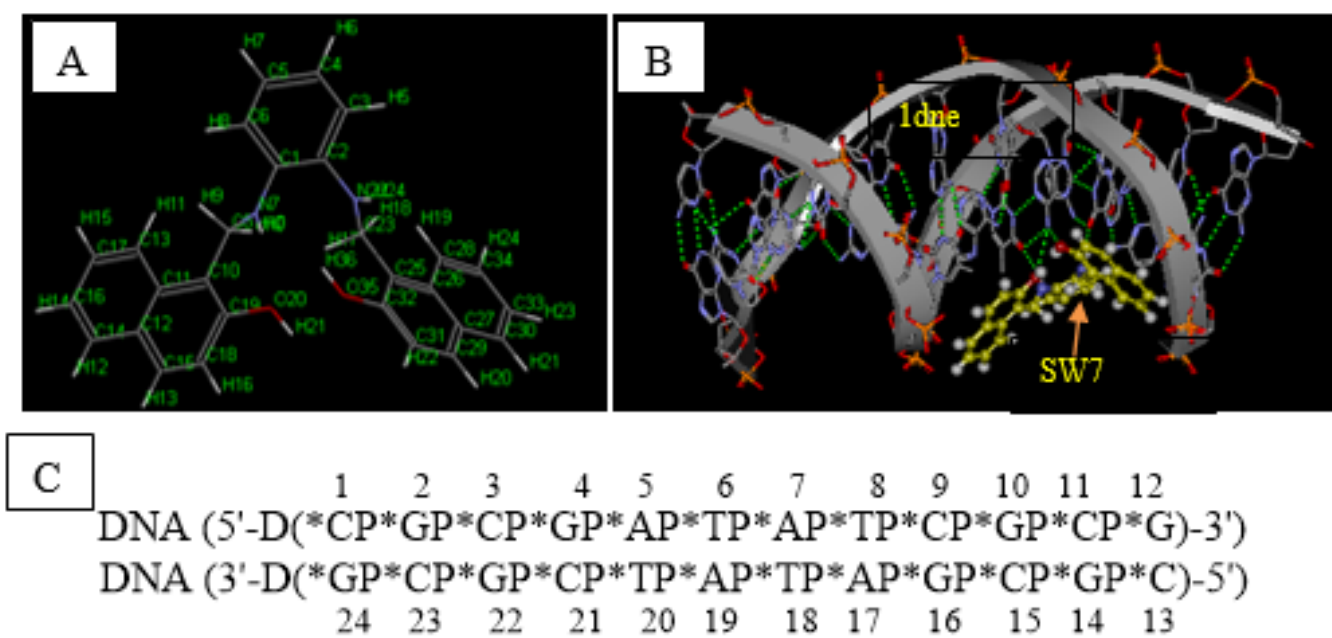

Figure1. (A) Chemical structure of the SW7 with atom numbering, (B) Double helical structure of 1dne hydrogen bound to the SW7 at the minor groove and $(C)$ double-stranded DNA sequence of Idne.

\section{CONCLUSION}

In conclusion, we have successfully performed in silico modelling for seven symmetrical 1,2phenylenediamine derivatives with seven DNA fragments. Relationships between hydrogen bond geometry and positioning of the SW compounds with the minor groove were studied. Docking studies suggest that molecular docking techniques may have particular value as a virtual screening precursor step to full chemical synthesis of drug candidates.

\section{REFERENCES}

[1] Kumar R, Lown JW. Design, synthesis and in vitro cytotoxic studies of novel bis-pyrrolo [2,1] [1,4] benzodiazepine-pyrrole and imidazole polyamide conjugates. Eur J Med Chem 2005; 40(7):641-654.

[2] Hu P, Chi HM, DeBacker KC, Gong X, Keim JH, Hsu IT, Snyder SA. Quaternary-centre-guided synthesis of complex polycyclic terpenes. Nature 2019.

[3] Thomas AM, He C, Zhao L, Galimova GR, Mebel AM, Kaiser RI. A Combined Experimental and Computational Study on the Reaction Dynamics of the 1-Propynyl (CH3CC) - 1,3-Butadiene $(\mathrm{CH} 2 \mathrm{CHCHCH} 2)$ System and the Formation of Toluene Under Single Collision Conditions. J Phys Chem A 2019.

[4] Sofian S. Mohamed, Inass A Al sadawi, Mohamed A Gbaj, Sami G. Alsabri, Nahd M Elmaki, Salah M. Bensaber, Anton Hermann, Abdul M. Gbaj. Microwave Assisted Synthesis and Antimicrobial Evaluation of Symmetrical 1,2-Phenylenediamine Schiff's Base derivatives. Pharmacy \& Pharmacology International Journal 2018; 6(5):344-348.

[5] Tiwari R, Mahasenan K, Pavlovicz R, Li C, Tjarks W. Carborane clusters in computational drug design: a comparative docking evaluation using AutoDock, FlexX, Glide, and Surflex. J Chem Inf Model 2009; 49(6):1581-1589.

[6] Yu B, Tian X, Zhang L, Feng R. Hematopoietic PBX-Interaction Protein Promotes Breast Cancer Sensitivity to Paclitaxel Through a Microtubule-Dependent Mechanism. DNA Cell Biol 2016; 35(11):740745 .

[7] Cheng HY, Zhang T, Qu Y, Shi WJ, Lou G, Liu YX, Zhang YY, Cheng L. Synergism between RIZ1 gene therapy and paclitaxel in SiHa cervical cancer cells. Cancer Gene Ther 2016; 23(11):392-395.

[8] Holt PA, Chaires JB, Trent JO. Molecular docking of intercalators and groove-binders to nucleic acids using Autodock and Surflex. J Chem Inf Model 2008; 48(8):1602-1615.

[9] Gilad Y, Senderowitz H. Docking studies on DNA intercalators. J Chem Inf Model 2014; 54(1):96-107.

[10] Hampshire AJ, Fox KR. The effects of local DNA sequence on the interaction of ligands with their preferred binding sites. Biochimie 2008; 90(7):988-998. 
Molecular Docking based Analysis to Elucidate DNA- 1, 2-Phenylenediamine Schiff's Base Derivative Interactions Promotes Chemotherapeutic Intervention

[11] Waring MJ. Overview of the interaction between chemotherapeutic agents and DNA. Drugs Exp Clin Res 1986; 12(6-7):441-453.

[12] Hassan AA, Aly AA, Mohamed NK, El Shaieb KM, Makhlouf MM, Abdelhafez EMN, Brase S, Nieger M, Dalby KN, Kaoud TS. Design, synthesis, and DNA interaction studies of furo-imidazo [3.3.3] propellane derivatives: Potential anticancer agents. Bioorg Chem 2019; 85:585-599.

[13] Mohan S, Rangappa S, Anilkumar NC, Fuchs JE, Bender A, Basappa, Rangappa KS, Bhatnagar R. Sulfated Ceria Catalyzed Synthesis of Imidazopyridines and Their Implementation as DNA Minor Groove Binders. Chem Biodivers 2019.

[14] Carter EK, Laughlin-Toth S, Dodd T, Wilson WD, Ivanov I. Small molecule binders recognize DNA microstructural variations via an induced fit mechanism. Phys Chem Chem Phys 2019; 21(4):1841-1851.

[15] Ho SN, Boyer SH, Schreiber SL, Danishefsky SJ, Crabtree GR. Specific inhibition of formation of transcription complexes by a calicheamicin oligosaccharide: a paradigm for the development of transcriptional antagonists. Proc Natl Acad Sci U S A 1994; 91(20):9203-9207.

[16] Ryabinin VA, Boutorine AS, Helene C, Denisov AY, Pyshnyi DV, Sinyakov AN. Oligonucleotide--minor groove binder 1:2 conjugates: side by side parallel minor groove binder motif in stabilization of DNA duplex. Nucleosides Nucleotides Nucleic Acids 2004; 23(6-7):953-968.

[17] Ryabinin VA, Boutorine AS, Helene C, Pyshnyi DV, Sinyakov AN. Oligonucleotide-minor groove binder conjugates and their complexes with complementary DNA: effect of conjugate structural factors on the thermal stability of duplexes. Nucleosides Nucleotides Nucleic Acids 2004; 23(5):789-803.

Citation: Abdul M Gbaj, et.al., (2019). Molecular Docking based Analysis to Elucidate DNA- 1, 2Phenylenediamine Schiff's Base Derivative Interactions Promotes Chemotherapeutic Intervention. ARC Journal of Pharmaceutical Sciences (AJPS), 5(3), pp.1-6. DOI: http://dx.doi.org/10.20431/24551538.0503001

Copyright: (C) 2019 Authors. This is an open-access article distributed under the terms of the Creative Commons Attribution License, which permits unrestricted use, distribution, and reproduction in any medium, provided the original author and source are credited. 